\title{
6

\section{The Learning Curve for Peroral Endoscopic Myotomy in Latin America: A Slide to the Right?}

\author{
Michel Kahaleh ${ }^{1}$, Amy Tyberg ${ }^{1}$, Supriya Suresh ${ }^{2}$, Arnon Lambroza ${ }^{2}$, Fernando Rodriguez Casas ${ }^{3}$, Mario Rey ${ }^{3}$, Jose Nieto ${ }^{4}$, \\ Guadalupe Ma Martínez ${ }^{5}$, Felipe Zamarripa ${ }^{5}$, Vitor Arantes ${ }^{6}$, Maria G Porfilio ${ }^{7}$, Monica Gaidhane', Pietro Familiari ${ }^{8}$, Juan Carlos \\ Carames $^{9}$, Romulo Vargas-Rubio ${ }^{10}$, Raul Canadas ${ }^{10}$, Albis Hani ${ }^{10}$, Guillermo Munoz ${ }^{1}$, Bismarck Castillo ${ }^{11}$, Eduardo T Moura ${ }^{12}$, Farias \\ F Galileu' ${ }^{12}$, Hannah P Lukashok ${ }^{13}$, Carlos Robles-Medranda ${ }^{13}$ and Eduardo G de Moura ${ }^{12}$
}

${ }^{1}$ Robert Wood Johnson University Hospital, New Brunswick, NJ, ${ }^{2}$ Weill Cornell Medical College, New York, NY, USA, ${ }^{3}$ La Policia, Bogota, Colombia, ${ }^{4}$ Borland-Groover, Jacksonville, FL, USA, ${ }^{5}$ Juarez Hospital, Mexico City, Mexico, ${ }^{6}$ Belo Horizonte Hospital, Belo Horizonte, Brazil, ${ }^{7}$ Hospital Escuela Dr. Ramon Madariaga, Posadas, Argentina, ${ }^{8}$ Gemelli University Hospital, Roma, Italy, ${ }^{9}$ Santander Hospital, Reynosa, Mexico, ${ }^{10}$ San Ignacio University Hospital, Bogota, Columbia, ${ }^{11}$ Gastromedica Clinic, Managua, Nicaragua, ${ }^{12}$ Gastrointestinal Endoscopy Unit, University of Sao Paulo, Sao Paulo, Brazil, ${ }^{13}$ Instituto Ecuatoriano de Enfermedades Digestivas, Guayaquil, Ecuador

Background/Aims: Peroral endoscopic myotomy (POEM) has been increasingly used for achalasia in Latin America, where Chagas disease is prevalent, and this makes POEM more challenging. The aim of this study was to determine the learning curve for POEM in Latin America.

Methods: Patients undergoing POEM in Latin America with a single operator were included from a prospective registry over 4 years. Non-linear regression and cumulative sum control chart (CUSUM) analyses were conducted for the learning curve.

Results: A total of 125 patients were included (52\% male; mean age, 59 years), of which 80 had type II achalasia (64\%), and 38 had Chagas disease (30\%). The average pre-procedure and post-procedure Eckardt scores were 6.79 and 1.87, respectively. Technical success was achieved in $93.5 \%$ of patients, and clinical success was achieved in $88.8 \%$. Adverse events occurred in 27 patients (22\%) and included bleeding (4 patients), pneumothorax (4 patients), mucosal perforation (13 patients), mediastinitis ( 2 patients), and leakage (4 patients).

The CUSUM chart showed a median procedure time of $97 \mathrm{~min}$ (range, 45-196 min), which was achieved at the 61st procedure. Procedure duration progressively decreased, with the last 10 procedures under $50 \mathrm{~min}$ approaching a plateau $(p$-value $<0.01)$. Conclusions: Mastering POEM in Latin America requires approximately 61 procedures for both POEM efficiency and to accomplish the procedure within 97 minutes. Clin Endosc 2021;54:701-705

Key Words: Achalasia; Chagas; Latin America, Learning Curve; Per oral endoscopic myotomy

\section{INTRODUCTION}

Peroral endoscopic myotomy (POEM) has been a minimally invasive treatment option for patients with achalasia

\author{
Received: November 4, 2020 Revised: February 5, 2021 \\ Accepted: February 6, 2021 \\ Correspondence: Michel Kahaleh \\ Robert Wood Johnson University Hospital, 1 RWJ Plaza, MEB 464, New Bruns- \\ wick, NJ 08901, USA \\ Tel: +1-732-235-3976, Fax: +1-732-235-5537, E-mail: mkahaleh@gmail.com \\ ORCID: https://orcid.org/0000-0003-0836-6114
}

(cc) This is an Open Access article distributed under the terms of the Creative Commons Attribution Non-Commercial License (http://creativecommons.org/ licenses/by-nc/3.0) which permits unrestricted non-commercial use, distribution, and reproduction in any medium, provided the original work is properly cited. for the past 10 years. Although comparable to laparoscopic Heller's myotomy (LHM) in terms of efficacy, POEM has the advantages of minimal invasiveness, allowance for a longer myotomy, and the ability to perform a posterior or anterior myotomy. ${ }^{1-6}$ After 10 years of consistent safety and efficacy, POEM is now being performed worldwide and has been increasingly used in Latin America where Chagas disease is prevalent. Reports on POEM for Chagas disease are scarce. ${ }^{71}$ POEM in Chagas disease is technically more challenging than in patients with achalasia, due to a higher rate of submucosal scarring, ${ }^{21}$ most likely related to chronic esophagitis caused by esophageal stasis (clinical observation, unpublished data). Two recently published studies have shown that Chagas disease-related achalasia responds better to POEM. ${ }^{15,22}$ Nonetheless, 
the learning curve of gastroenterologists performing the procedure has not been well studied. ${ }^{16-21}$ The aim of this study was to determine the learning curve for POEM among operators in Latin America.

\section{PATIENTS AND METHODS}

Consecutive patients diagnosed with achalasia who underwent POEM with a single operator in Argentina, Bolivia, Brazil, Colombia, Ecuador, Mexico, and Nicaragua between June 2013 and August 2017 were included in a prospective registry (ClinicalTrials.gov Identifier: NCT02162589). The single operator was previously proficient in endoscopic submucosal dissection (ESD). Informed consent for the procedure was obtained from all patients. Patient demographics, procedural information, post-procedural follow-up data, and adverse events were collected for all patients. Technical success was defined as successful completion of the myotomy. Clinical success was defined as an Eckardt score of $\leq 3$ at 3 months.

\section{Procedural technique}

All procedures were performed under general anesthesia with endotracheal intubation. $\mathrm{CO}_{2}$ insufflation was used in all cases. A standard gastroscope fitted with a dissection cap was used. Initial upper endoscopy to clear the esophagus was performed, after which a mixture of saline solution and methylene blue was injected anteriorly or posteriorly. A longitudinal incision was made and a $12-\mathrm{cm}$ longitudinal tunnel was created crossing the esophagogastric junction $2 \mathrm{~cm}$ into the stomach. The myotomy was performed in this tunnel. Ultimately, the mucosotomy was closed with endoscopic clips.

\section{Clinical outcomes and statistical analysis}

Demographics, clinical characteristics, pre- and post-procedure Eckardt scores, procedure duration, post-procedure follow-up data, and adverse events were collected. To measure the learning curve, non-linear regression was used with the case number as an independent variable and the procedure time as the dependent variable.

Cumulative sum control chart (CUSUM) analysis was conducted to report small shifts in procedure duration over time. The CUSUM analysis was performed similar to the modeling described by Biau DJ et al. ${ }^{23}$ Non-linear regression, CUSUM analyses test for independent means, and Fisher exact tests for proportions were conducted using Stata 15 (StataCorp LLC, College Station, TX, USA). The primary outcome was the analysis of the learning curve, which was obtained by measuring the length of the procedure for consecutive procedures. The secondary outcomes were technical clinical efficacy based on the postoperative Eckardt score, adverse event rate, and reintervention rate.

\section{RESULTS}

Table 1 summarizes the main results of this study. A total of 125 patients were included (52\% male; mean age, 59 years). The most common pathology was type II achalasia $(n=80$, $64 \%)$, followed by type I achalasia ( $n=9,7.2 \%)$, type III achalasia $(n=33,26.4 \%)$, and other esophageal motility disorders $(n=3,2.4 \%)$. Chagas disease was present in approximately one-third of the patients $(n=38,30.4 \%)$. Most patients had undergone no prior treatment for achalasia $(n=84,67.2 \%)$. Previous treatments undergone by patients included prior LHM $(n=18,14.4 \%)$, pneumatic dilation $(n=17,13.6 \%)$, or botulinum toxin injections $(n=6,4.8 \%)$. The average pre-procedure Eckardt score was 6.79.

Technical success was achieved in $93.5 \%$ of patients $(n=117)$. A total of 99 patients $(79.2 \%)$ underwent posterior POEM, and 26 patients underwent anterior POEM (20.8\%). The mean procedure duration in all cases was $97 \mathrm{~min}$, ranging from $45 \mathrm{~min}$ to $196 \mathrm{~min}$, with a mean of $102.7 \mathrm{~min}$. There was no statistically significant difference $(p=0.35)$ in the mean procedure duration of the Chagas group (mean $=108 \mathrm{~min}$; range, 48-196 $\mathrm{min}$ ), when compared to that in the non-Chagas patients (mean $=100.36 \mathrm{~min}$; range, $46-175 \mathrm{~min}$ ).

Mucosotomy entry was closed with standard endoclips in the majority of patients $(n=120,96 \%)$. Only in 5 cases (4\%) were the mucosotomy closed with overstitch sutures.

Clinical success was achieved in 111 patients (88.8\%). The mean post-procedure Eckardt score was 1.87. The clinical failure rate was higher in the Chagas group than in the non-Chagas group ( $21 \%$ vs. $7 \%, p=0.03$ ).

On average, the median length of hospital stay was 1.98 days. The median follow-up period was 16 months (standard deviation [SD] , 12.89 months).

Adverse events occurred in 27 patients (21.6\%) and included mucosal perforation $(n=13,10.4 \%)$ closed during a second endoscopy by using clips, severe bleeding $(n=4,3.2 \%)$ solved using coagulation graspers and balloon tamponade, pneumothorax $(n=4,3.2 \%)$ requiring chest tube placement, leak $(n=4,3.2 \%)$ that resolved on repeat endoscopy and clip closure, and mediastinitis $(n=2,1.6 \%)$ managed with antibiotic therapy. The incidence of adverse events was higher in the Chagas group than that in the non-Chagas group ( $37 \%$ vs. $15 \%, p=0.01$ ).

There was no statistically significant difference in reintervention rates between the Chagas group and the non-Chagas group ( $18 \%$ vs. $7 \%, p=0.06)$. 
Table 1. Summary of Demographics and Results

\begin{tabular}{|c|c|}
\hline$N=125$ & \\
\hline Male:Female & $65: 60$ \\
\hline Age (years) & \\
\hline Mean (SD) & $59.14(12.48)$ \\
\hline Achalasia Type & 122 \\
\hline • Type I & 9 \\
\hline • Type II & 80 \\
\hline - Type III & 33 \\
\hline - Jackhammer esophagus & 2 \\
\hline - Nutcracker esophagus & 1 \\
\hline Chagas disease (\%) & $38(30.4 \%)$ \\
\hline Prior treatments & \\
\hline - Heller myotomy (\%) & $18(14.4 \%)$ \\
\hline - Pneumatic dilation (\%) & $17(13.6 \%)$ \\
\hline - Botulinum toxin (\%) & $6(4.8 \%)$ \\
\hline No prior treatments & $84(67.2 \%)$ \\
\hline Pre-procedure & \\
\hline Mean Eckardt score (SD) & $6.79(2.05)$ \\
\hline Mean LES pressure (mmHg) & 29.04 \\
\hline Orientation & \\
\hline Anterior:Posterior & $26: 99$ \\
\hline Device for closure & \\
\hline Clips:Overstitch suture & $120: 5$ \\
\hline Post-procedure (3 months) & \\
\hline Mean Eckardt score (SD) & $1.87(2.15)$ \\
\hline Mean LES pressure (mmHg) & 22.56 \\
\hline Technical success & $117(93.5 \%)$ \\
\hline Clinical success & $111(88.8 \%)$ \\
\hline Complications & \\
\hline - Bleeding & 4 \\
\hline - Pneumothorax & 4 \\
\hline - Mucosal perforation & 13 \\
\hline - Mediastinitis & 2 \\
\hline - Leak & 4 \\
\hline Interventions for complications & \\
\hline - Hemoclips (mucosal perforations) & 12 \\
\hline - Overscope clips (mucosal perforations) & 1 \\
\hline - Needle decompression (pneumothorax) & 1 \\
\hline - Chest tubes (pneumothorax) & 3 \\
\hline - Coagulation (bleeding) & 1 \\
\hline - Reclips (leaks) & 4 \\
\hline - Antibiotics (mediastinitis) & 2 \\
\hline Procedure time (minutes, SD) & $102.65(42.48)$ \\
\hline Hospital stay (days, SD) & $1.98(0.97)$ \\
\hline Follow up duration (months, SD) & $16(12.89)$ \\
\hline Reinterventions & \\
\hline - Heller myotomy & 5 \\
\hline - Pneumatic dilation & 8 \\
\hline
\end{tabular}

LES, lower esophageal sphincter; SD, standard deviation.

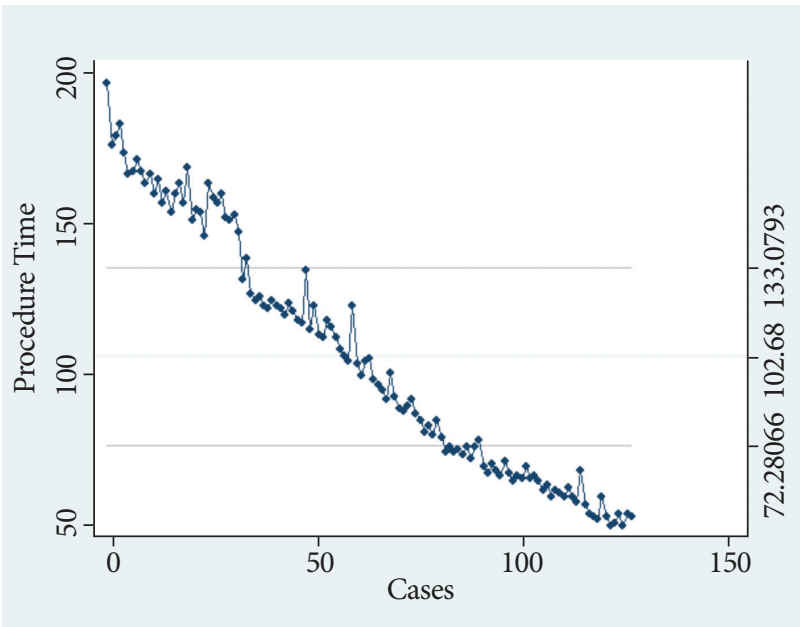

Fig. 1. Cumulative sum control chart shows procedure efficiency duration.

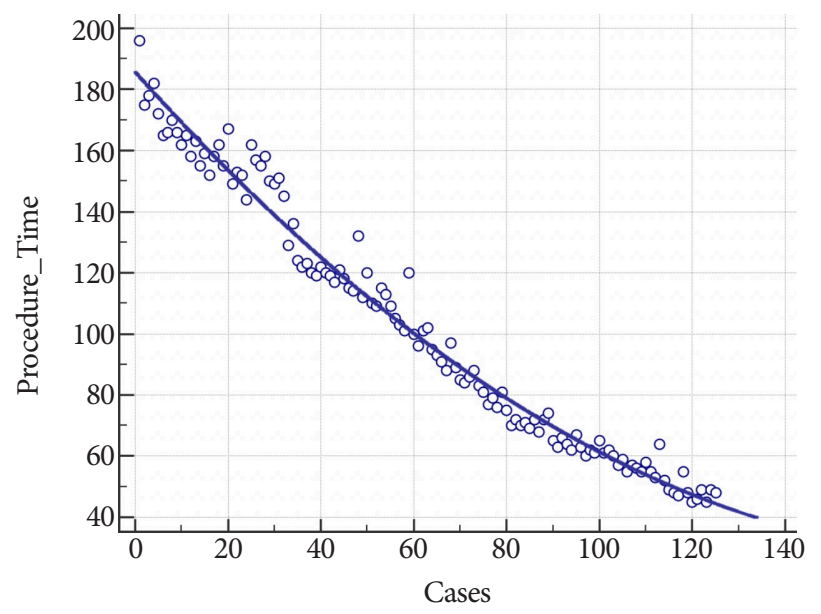

Fig. 2. Inverse curve regression showing procedure time decrease significantly over the course of consecutive procedures.

The CUSUM analysis (Fig. 1) revealed that the 97-minute procedure time was achieved at the 61st procedure, indicating efficiency. Aside from a few outliers, procedure duration further reduced with consequent procedures with the last 10 procedures under 50 minutes almost approaching a plateau (non-linear regression, $p<0.01$ ) (Fig. 2). We assume that further evaluation of the next 40-50 cases could potentially reveal a plateau, indicating mastery.

\section{DISCUSSION}

POEM has been well-established as a safe and efficacious procedure for the management of achalasia. In a meta-analysis of 36 studies that included 2,373 patients across 12 countries, 
$98 \%$ of patients with achalasia had clinical success (defined as a reduction in Eckardt score to $\leq 3$ ) with POEM. The mean Eckardt score decreased from $6.9 \pm 0.15$ preoperatively to $1.0 \pm 0.08$ at 12 months postoperatively. In addition, there were significant decreases in the average lower esophageal sphincter pressure and the integrated relaxation pressure. ${ }^{24}$

Previous studies have suggested that POEM in Chagas patients is technically more challenging due to significant amounts of submucosal scarring. ${ }^{15}$ However, studies also suggest that patients with Chagas disease-related achalasia tend to respond better to POEM than to $\mathrm{LHM}^{15}$

Another recent study comparing POEM in Chagas vs. non-Chagas achalasia patients highlighted how the post-procedure Eckardt scores, procedure time, and repeat interventions differed between the groups. In the Chagas group, the post-procedure Eckardt score was reduced by 3.57 points compared to 6.03 in the non-Chagas group. Repeat intervention was much higher in the Chagas group than in the non-Chagas group (51\% vs. 17\%), and the mean POEM procedure time was longer in the Chagas group than in the non-Chagas group (120 minutes vs 94 minutes). ${ }^{22}$

In this study, we saw statistically significant higher adverse events and clinical failure rates in the Chagas group than in the non-Chagas group (37\% vs. $15 \%$ and $21 \%$ vs. $7 \%$, respectively).

There is limited published information on the learning curve of this procedure which includes achalasia patients due to Chagas disease. Kurian et al. looked at the learning curve of POEM and reported mastery of technique after 20 operations, demonstrated by decreased procedural time. ${ }^{11}$ Patel et al. evaluated the experience of a single gastroenterologist's POEM learning curve in which they found that efficiency was achieved after 40 cases and mastery was reached after 60 operations. ${ }^{12}$ Zein et al. analyzed multiple methodologies for assessing the learning curve and reported a learning rate of 13 cases and a "plateau" at 102 minutes. ${ }^{13}$ Liu et al. found that 100 cases were required to decrease the risk of technical failure, adverse events, and clinical failure, while 70 cases were the threshold for decreasing procedure time. ${ }^{9}$ A recent study of 136 patients by Tefas et al. ${ }^{25}$ reported a learning curve cut-off of 20 cases. They also noted that the major complication risk rate was higher during the learning curve (13.3\%). However, the rate of minor complications was not influenced by operator competency during or after the learning curve cut-off.

Our study differs from the previous POEM learning curve studies as our analyses included Chagas patients, reflecting actual endoscopic experiences in the achalasia patient population in Latin America. Of the 125 patients included in the study, 30\% had Chagas disease and the Chagas group had a higher incidence of adverse event rates than the non-Chagas group. There was no statistically significant difference in the procedure times between the groups, and the median procedure time was 97 minutes.

CUSUM analyses showed that a 97 minute procedure time was achieved at the 61st procedure and procedure duration progressively decreased, with the last 10 procedures performed in less than 50 minutes.

There are two limitations to this study. We did not compare multiple operators. Additionally, the expert endoscopist included in this study had prior proficiency in therapeutic endoscopy, including endoscopic submucosal dissection (ESD) and endoscopic mucosal resection (EMR). Thus, the learning curve might underestimate the number of therapeutic endoscopies and POEMs required to achieve POEM proficiency in endoscopists who lack such skills.

\section{CONCLUSIONS}

This Latin America learning curve study demonstrated that efficiency was reached at 97 minutes and at a learning rate of 61 cases, with continuing improvement. POEM seems to be a more technically difficult procedure to master in Latin America, requiring a higher volume of cases to reach efficiency, and also seems to be associated with a higher number of adverse events in the initial phase of the learning curve. Most likely, these obstacles are related to the increased anatomical challenges observed in patients with Chagas disease. We recommend that only endoscopists demonstrating proficiency in ESD and EMR should conduct POEM procedures.

\section{Conflicts of Interest}

Amy Tyberg has done consulting work for Nine Point Medical, Endo Gastric Solutions, and Obalon Therapeutics. She is a board director at the Therapeutic EUS Society Inc. Michel Kahaleh has done consulting work for Boston Scientific, Interscope Med, Obalon Therapeutics, and Abbvie. He has received research grants from Boston Scientific, Conmed, Pinnacle, Cook, Gore, Merit, and Olympus. He is the CEO of Innovative Digestive Health Education \& Research Inc. and the Therapeutic EUS Society Inc. M. Kahaleh has received grant support from Boston Scientific, Fujinon, W.L. Gore, Mauna Kea, Apollo Endosurgery, Cook Endoscopy, ASPIRE Bariatrics, GI Dynamics, Nine Point Medical, Merit Medical, Interscope Med, Olympus, ERBE, and MI Tech. He is a consultant for Boston Scientific, Concordia Laboratories Inc., ABBvie, and Mauna Kea Tech. None of the funding was related to this study. Monica Gaidhane has done consulting work for Interscope Med. She is the COO of Innovative Digestive Health Education \& Research Inc. and the Therapeutic EUS Society Inc. The other authors have no potential conflicts of interest.

$$
\begin{aligned}
& \text { Funding } \\
& \text { None. } \\
& \text { ORCID } \\
& \quad \text { Michel Kahaleh: } \quad \text { https://orcid.org/0000-0003-0836-6114 }
\end{aligned}
$$


Amy Tyberg:

Supriya Suresh:

Arnon Lambroza:

Fernando Rodriguez Casas:

Mario Rey:

Jose Nieto:

Guadalupe Ma Martínez:

Felipe Zamarripa:

Vitor Arantes:

Maria G Porfilio:

Monica Gaidhane:

Pietro Familiari:

Juan Carlos Carames:

Romulo Vargas-Rubio:

Raul Canadas:

Albis Hani:

Guillermo Munoz:

Bismarck Castillo:

Eduardo T Moura:

Farias F Galileu:

Hannah P Lukashok:

Carlos Robles-Medranda:

Eduardo G de Moura: https://orcid.org/0000-0001-5760-8170 https://orcid.org/0000-0002-3907-0984 https://orcid.org/0000-0002-9411-4740 https://orcid.org/0000-0003-3418-172X https://orcid.org/0000-0002-5870-3185 https://orcid.org/0000-0001-9595-8120 https://orcid.org/0000-0003-2551-2902 https://orcid.org/0000-0002-7758-9947 https://orcid.org/0000-0001-8000-5298 https://orcid.org/0000-0003-3699-9963 https://orcid.org/0000-0001-6773-7080 https://orcid.org/0000-0003-0513-2312 https://orcid.org/0000-0002-5070-2751 https://orcid.org/0000-0001-5660-6229 https://orcid.org/0000-0003-2938-7731 https://orcid.org/0000-0002-9219-4548 https://orcid.org/0000-0001-8894-6607 https://orcid.org/0000-0002-8206-4723 https://orcid.org/0000-0003-1531-825X https://orcid.org/0000-0003-0242-3691 https://orcid.org/0000-0002-4364-1321 https://orcid.org/0000-0003-2434-3369 https://orcid.org/0000-0002-8023-3722

\section{REFERENCES}

1. Inoue $\mathrm{H}$, Minami $\mathrm{H}$, Kobayashi $\mathrm{Y}$, et al. Peroral endoscopic myotomy (POEM) for esophageal achalasia. Endoscopy 2010;42:265-271.

2. Stavropoulos SN, Modayil RJ, Friedel D, Savides T. The international per oral endoscopic myotomy survey (IPOEMS): a snapshot of the global POEM experience. Surg Endosc 2013;27:3322-3338.

3. Crespin OM, Liu LWC, Parmar A, et al. Safety and efficacy of POEM for treatment of achalasia: a systematic review of the literature. Surg Endosc 2017;31:2187-2201.

4. Li H, Peng W, Huang S, et al. The 2 years' long-term efficacy and safety of peroral endoscopic myotomy for the treatment of achalasia: a systematic review. J Cardiothorac Surg 2019;14:1.

5. Stavropoulos SN, Modayil R, Friedel D. Per oral endoscopic myotomy for the treatment of achalasia. Curr Opin Gastroenterol 2015;31:430440 .

6. Tantau M, Crisan D. Peroral endoscopic myotomy: time to change our opinion regarding the treatment of achalasia? World J Gastrointest Endosc 2015;7:237-246.

7. von Rahden BHA. [Current treatment of achalasia 2019]. Zentralbl Chir 2019;144:163-170.

8. Pescarus R, Shlomovitz E, Swanstrom LL. Per-oral endoscopic myotomy (POEM) for esophageal achalasia. Curr Gastroenterol Rep 2014;16:369.

9. Liu Z, Zhang X, Zhang W, et al. Comprehensive evaluation of the learning curve for peroral endoscopic myotomy. Clin Gastroenterol Hepatol 2018;16:1420-1426.e2.

10. Tanțău M, Buzaş C, Tefas C, Groza A, Tanțău A. "Learning curve" for the POEM procedure. J Gastrointestin Liver Dis 2015;24:536-537.

11. Kurian AA, Dunst CM, Sharata A, Bhayani NH, Reavis KM, Swanström LL. Peroral endoscopic esophageal myotomy: defining the learning curve. Gastrointest Endosc 2013;77:719-725.

12. Patel KS, Calixte R, Modayil RJ, Friedel D, Brathwaite CE, Stavropoulos SN. The light at the end of the tunnel: a single-operator learning curve analysis for per oral endoscopic myotomy. Gastrointest Endosc 2015;81:1181-1187.

13. El Zein M, Kumbhari V, Ngamruengphong S, et al. Learning curve for peroral endoscopic myotomy. Endosc Int Open 2016;4:E577-E582.

14. Zaninotto G, Bennett C, Boeckxstaens G, et al. The 2018 ISDE achalasia guidelines. Dis Esophagus 2018;31:1-29.

15. Kahaleh $\mathrm{M}, \mathrm{Xu}$ M-M, Zamarripa F, et al. POEM in Latin America: the rise of a new standard. J Clin Gastroenterol 2019;53:e352-e355.

16. Teitelbaum EN, Soper NJ, Arafat FO, et al. Analysis of a learning curve and predictors of intraoperative difficulty for peroral esophageal myotomy (POEM). J Gastrointest Surg 2014;18:92-98; discussion 98-99.

17. Nabi Z, Reddy DN, Ramchandani M. Adverse events during and after per-oral endoscopic myotomy: prevention, diagnosis, and management. Gastrointest Endosc 2018;87:4-17.

18. Wang Y, Liu Z-Q, Xu M-D, et al. Clinical and endoscopic predictors for intraprocedural mucosal injury during per-oral endoscopic myotomy. Gastrointest Endosc 2019;89:769-778.

19. Hungness ES, Sternbach JM, Teitelbaum EN, Kahrilas PJ, Pandolfino JE, Soper NJ. Per-oral endoscopic myotomy (POEM) after the learning curve: durable long-term results with a low complication rate. Ann Surg 2016;264:508-517.

20. Lv H, Zhao N, Zheng Z, et al. Analysis of the learning curve for peroral endoscopic myotomy for esophageal achalasia: single-center, two-operator experience. Dig Endosc 2017;29:299-306.

21. Vaz Â, Ferrari TA, Gomes RV, Arantes VN. Peroral endoscopic myotomy for management of megaesophagus due to Chagas disease. Relatos Casos Cir 2016;1:1-3.

22. Kahaleh M, Tyberg A, Suresh S, et al. How does per-oral endoscopic myotomy compare to Heller myotomy? The Latin American perspective. Endosc Int Open 2020;8:E1392-E1397.

23. Biau DJ, Williams SM, Schlup MM, Nizard RS, Porcher R. Quantitative and individualized assessment of the learning curve using LC-CUSUM. Br J Surg 2008;95:925-929.

24. Akintoye E, Kumar N, Obaitan I, Alayo QA, Thompson CC. Peroral endoscopic myotomy: a meta-analysis. Endoscopy 2016;48:1059-1068.

25. Tefas C, Boroș C, Ciobanu L, Surdea-Blaga T, Tanțău A, Tanțău M. POEM: five years of experience in a single east european center. J Gastrointestin Liver Dis 2020;29:323-328 . 